\title{
DOSSIÊ
}

\section{Fazer história: o estatuto das fontes e o lugar dos acervos nas pesquisas de história de arquitetura e da cidade no Brasil}

\section{Introdução}

\author{
Ana Claudia Veiga de Castro ${ }^{1}$ \\ Joana Mello de Carvalho e Silva ${ }^{2}$ \\ Entretanto acontece com isso o mesmo que com a caça às \\ borboletas; o pobre animal treme na rede, perde suas mais belas \\ cores; e quando se apanha de supetão, está finalmente duro e \\ sem vida; o cadáver não faz todo o animal, há alguma coisa a \\ mais, uma parte essencial e nesse caso, como em todo outro, \\ uma parte essencialmente essencial: a vida.

\begin{abstract}
1. Arquiteta e urbanista, docente da graduação e da pós-graduação da Faculdade de Arquitetura e Urbanismo (FAU) da Universidade de São Paulo (USP). E-mail: <anacvcastro@usp.br>.

2. Arquiteta e urbanista, docente da graduação e da de de Arquitetura e Urbanismo da USP. E-mail: <joana-mello@usp.br>.
\end{abstract} \\ pós-graduação da Faculda-
}

Goethe, Carta a Hetzler, 1770

Cidade e arquitetura são objetos de pesquisa que apresentam uma multiplicidade de abordagens e de interpretações. Se ambas podem ser vistas a partir de suas características materiais, parece igualmente importante, ao se buscar construir as suas narrativas históricas, recuperar aquilo que Goethe lembrava como "uma parte essencialmente essencial: a vida". Pode-se afirmar sem constrangimentos que esse tem sido um dos caminhos de pesquisa mais profícuos nos últimos tempos, incorporando-se às interpretações, além das dimensões técnicas e disciplinares, a dimensão humana da cidade e da arquitetura.

Ao recuperarmos o caminho que os estudos no campo seguiram no Brasil com a consolidação dos programas de pós-graduação em arquitetura e urbanismo, entre os anos de 1980 e 1990, juntamente a um conjunto significativo 
3. Merecem destaque pela contribuição na formação dos pesquisadores que aqui escrevem, e pelos diálogos estabelecidos com os seus trabalhos, os programas e grupos de pesquisa estabelecidos na Faculdade de Arquitetura e Urbanismo da Universidade de São Paulo (FAUUSP), no Instituto de Arquitetura e Urbanismo da USP (IAU USP), e nas faculdades de Arquitetura e Urbanismo da Universidade Federal do Rio Grande do Sul (FAU UFRGS), da Universidade Federal do Rio de Janeiro (FAU UFRJ), da Universidade de Brasília (FAU UnB) e da Universidade Federal da Bahia (FAU UFBA). Dos eventos, destacam-se o Seminário de História da Cidade e do Urbanismo (SHCU), os encontros da Associação Nacional de Pesquisa e Pós-Graduação em Arquitetura (Anparq) e da Associação Nacional de Pós-Graduação e Pesquisa em Planejamento Urbano e Regional (Anpur), bem como o Seminário Ibero-Americano Arquitetura e Documentação e o recém-criado Seminário Ibero-americano de História Urbana. Ainda deve-se mencionar os seminários promovidos pela representação brasileira da organização não governamental Documentation and Conservation of Buildings, Sites and Neighbourghoods of Moderna Movement (Do. co.mo.mo), que também contribuiu para tais aprofundamentos.

4. Para um breve histórico da consolidação dos dois campos, ver Ana Claudia Veiga de Castro e Joana Mello de Carvalho e Silva (2016). de eventos acadêmicos, ${ }^{3}$ notamos, por um lado, um progressivo distanciamento da prática projetual - o que sem dúvida contribuiu para a autonomização das pesquisas em história -, e, por outro, uma aproximação às ciências humanas, num "processo controlado de empréstimos recíprocos" em que se incentivou a interdisciplinaridade (SALGUEIRO, 2001, p. 16).

Nesse percurso, houve uma ampliação e diversificação não apenas do número de pesquisas nessa área, mas das próprias tipologias documentais mobilizadas, incorporando-se, para além de fontes mais afeitas ao campo, como planos urbanos e projetos de arquitetura, um sem-número de outros artefatos que passaram também a ser vistos como documentos (LE GOFF, 1990, p. 535-553). Ao mesmo tempo, referenciais teóricos de outras disciplinas, sobretudo os da História, mas ainda da Sociologia, Antropologia, Psicologia, Economia, entre outros, passaram a alimentar investigações que revisavam temas e agentes de narrativas consagradas e formulavam novos objetos de pesquisa, contribuindo para um aprofundamento historiográfico significativo. ${ }^{4}$ A sofisticação dessas abordagens e análises produziram ao longo do tempo obras de referência fundamentais para a formação de novas gerações, incentivando a continuidade da reflexão pelos jovens pesquisadores que aprofundariam as pesquisas, formulando novos problemas e estabelecendo novas linhas de investigação.

Como um passo decorrente dos avanços conseguidos até aqui, e considerando as especificidades da cidade e da arquitetura como objetos de estudo da História, parece oportuno refletir de maneira mais detida sobre questões teórico-metodológicas atinentes à área. Do nosso ponto de vista, tanto a cidade como a arquitetura devem ser entendidas como construções sócio-históricas que envolvem relações diversas e assumem sentidos culturais complexos, exigindo para a sua análise uma multiplicidade de escalas de observação, sem se definir previamente hierarquias entre macro e microfenômenos (REVEL, 1996; LEPETIT, 2001, p. 191-226).

Compartilhamos daquilo que Bernard Lepetit nomeou de uma compreensão "sistêmica" da cidade, e também da arquitetura, na qual o objeto a ser investigado é sempre entendido dentro de um sistema que o engloba e, ao mesmo tempo, analisado ele próprio como um sistema cujos elementos ganham sentido uns em relação aos outros (LEPETIT, 2001, p. 56). Isso implica em considerar as dimensões de artefato da arquitetura e da cidade como coisa fabricada, mas que geram e suportam um complexo campo de forças econômicas, territoriais, especulativas, políticas, sociais e culturais, historicamente produzidas a partir do envolvimento de diversos agentes, comportando ainda uma terceira dimensão, também fundamental, da representação (MENESES, 1996, p. 149). Frente a essa abrangência conceitual e analítica, e ao fato de que o passado não é simplesmente conservado, mas reconstruído na história continuamente por meio de problemas, a escolha das escalas de abordagem define, além de um ponto de vista, estratégias e possibilidades de conhecimento, assumindo não apenas um papel descritivo, mas também explicativo (LE GOFF, 1990; LEPETIT, 2001). 
Os artigos que compõem o dossiê Fazer história: o estatuto das fontes e o lugar dos acervos nas pesquisas de história da arquitetura e da cidade no Brasil compartilham dessa compreensão. Partindo de trabalhos anteriores comprometidos com as revisões historiográficas em curso no campo da arquitetura, da cidade, da habitação e do patrimônio acima mencionadas, os autores reunidos neste dossiê apresentam os andaimes teórico-metodológicos de suas pesquisas, enfatizando as relações entre problemas históricos, fontes e arquivos. Seus trabalhos foram desenvolvidos individual e coletivamente em diferentes instituições, apresentados e debatidos em eventos acadêmicos e no cotidiano da prática docente, incorporando críticas e sugestões, e avançando em seus resultados.

Esse diálogo teve início, em 2010, no I Encontro Nacional da Associação Nacional de Pesquisa e Pós-Graduação em Arquitetura e Urbanismo (Enanparq) com a mesa Leituras, diálogos e conflitos: as relações no espaço construído e imaginado entre Brasil, América e Europa, da qual participaram Ana Claudia Veiga de Castro, Artemis Rodrigues Fontana, Fernando Atique, Flávia Brito do Nascimento, Joana Mello de Carvalho e Silva, Maria Luiza de Freitas, Marianna Boghosian Al Assal e Silvana Barbosa Rubino. Uma nova rodada de discussões, intitulada Diálogos e conflitos no espaço construído e imaginado entre Brasil, América e Europa, foi apresentada, em 2012, no XI Congresso Internacional da Brazilian Studies Association (Brasa). Nessa oportunidade, foram incorporados ao grupo os pesquisadores Dinalva Derenzo Roldan, Michelly Ângelo, Sabrina Studart Fontenelle Costa, Sidney Piocchi Bernardini e Nilce Aravecchia-Botas. As conversas e trocas de experiências travadas nesses encontros animaram a proposição de dois simpósios temáticos articulados, Documentos e arquivos da história da arquitetura e da cidade: problemas e métodos I e II, realizados no III Enanparq, em 2014, ganhando as contribuições dos pesquisadores Amália Cristóvão dos Santos, Eduardo Augusto Costa e Fernanda Pitta e avançando a partir dos comentários de Paulo Cesar Garcez Marins.

Como desdobramento dessas reflexões e no intuito de consolidá-las, criamos, em 2015, um grupo de pesquisa, Teoria e Método em História da Arquitetura e da Cidade, no Conselho Nacional de Desenvolvimento Científico e Tecnológico (CNPq). ${ }^{5}$ Um primeiro resultado do grupo foi apresentado no Simpósio Temático Teoria e método em História da Arquitetura e da cidade, durante o IV Enanparq (2016), buscando ampliar a rede de pesquisadores interessados em discutir as questões teórico-metodológicas indicadas a partir da perspectiva da história cultural e transnacional. ${ }^{6}$

Esse dossiê, que compõe mais um desses resultados, recupera o conjunto de discussões travadas especialmente durante o III Enanparq que seguiram sendo debatidas em outros fóruns e em muitos casos refletem o avanço das próprias pesquisas. Isso permitiu reformulações importantes em cada texto, no sentido de precisar questões, refinar argumentos e aprofundar a compreensão e o manejo dos instrumentos teórico-metodológicos escolhidos. Publicá-los aqui permite ao debate uma nova etapa. Convém notar que, diferentemente do que foi apresentado no III
5. O grupo conta atualmente com oito pesquisadores: Ana Claudia Veiga de Castro, Joana Mello de Carvalho e Silva, que coordenam o grupo, e ainda Amália dos Santos, Eduardo Costa, Fernanda Pitta, Flávia Brito do Nascimento, Marianna Boghosian, Nilce Aravecchia e Julianne Bellot Rolemberg Lessa.

6. Também como resultado do grupo destaca-se a criação da disciplina História da Arquitetura e da cidade: Teoria e Método dentro do PPG - FAUUSP, oferecida desde 2015. 
Enanparq, os artigos ora publicados enfatizam a reflexão acerca das relações entre problemas históricos e fontes documentais, procurando historicizar a sua produção, difusão e consumo, motivo pelo qual, em alguns casos específicos, também os arquivos foram objeto de análise crítica.

Várias são as possibilidades de diálogo e cruzamentos entre os textos, mas priorizou-se na organização desse dossiê um movimento que parte da reflexão dos arquivos, caminha para a análise dos documentos e volta aos arquivos, numa espécie de círculo analíico que engloba da escala do edifício à da cidade e a partir dela volta-se ao edifício, no qual arquivos, documentos e escalas de abordagem diversas perpassam todos os trabalhos em enfoques variados.

Outro ponto comum aos trabalhos do grupo, deve-se notar, é a filiação teórica, explícita ou implícita, à Escola dos Annales e seus desdobramentos, evidenciada na recuperação do passado sempre a partir de questões do presente, considerando-se a multiplicidade do tempo histórico e a necessidade da aproximação às demais ciências sociais. Se esse caminho não é particular dos Annales, é evidente que a força dessa escola historiográfica no Brasil e, em particular, na Universidade de São Paulo, impregna os trabalhos aqui reunidos (NOVAIS; SILVA, 201 1, p. 7-70). Não à toa, a atenção em todos os trabalhos ao estatuto das fontes de pesquisa, tomando como documento "tudo o que, pertencendo ao homem, depende do homem, serve o homem, exprime o homem, demonstra a presença, a atividade, os gostos e as maneiras de ser do homem", como já formulou uma vez Jacques Le Goff, mas sem jamais esquecer o papel fundamental da crítica a esse documento como um "monumento" (LE GOFF, 1990, p. 540).

O artigo que abre o dossiê, Da fotografia à cultura visual: Arquivo Fotográfico e práticas de preservação do Iphan, assinado por Eduardo Augusto Costa, desconstrói a lógica, a estrutura, o funcionamento e o discurso do arquivo fotográfico daquela instituição, revelando seu papel-chave na construção da narrativa da história da arquitetura e do patrimônio no Brasil. Dominando a historiografia em ambos os campos, o autor contribui para o debate ao apontar a centralidade que a fotografia assumiu na organização e manutenção do projeto cultural para o país encampado pelo lphan desde a sua fundação. Centralidade esta que envolveu usos diversos da fotografia, seja como registro supostamente objetivo, seja como prova do bem em análise em seu estado dito original, seja como obra acabada; definidos conforme intenções específicas que o autor recupera com precisão ao investigar os conjuntos documentais que compõem o referido arquivo e a sua organização. Assim, além da atenção ao arquivo, o autor ilumina o estatuto da fotografia como fonte, um documento recorrente entre os historiadores da arquitetura e do patrimônio, nem sempre objeto de uma crítica acurada e circunstanciada.

Se o Arquivo Fotográfico do Iphan surgiu a partir de uma concepção clara de arquitetura e patrimônio nacional, cuja imagem se procurou controlar a partir da seleção e circulação rigorosa de imagens, como revela Costa, o Acervo de Projetos da FAUUSP - também aqui analisado - foi resultado de um conjunto 
de contingências que garantiu a guarda de diversas propostas e práticas arquitetônicas. A diferença, como procura mostrar Joana Mello de Carvalho e Silva no artigo Um acervo, uma coleção e três problemas: a Coleção Jacques Pilon da Biblioteca da FAUUSP, tem relação com as especificidades do processo de constituição dos campos profissional e historiográfico da arquitetura. Além da análise aprofundada do acervo em questão, também ele entendido como um constructo sócio-histórico, a autora se dedica a criticar os documentos ali guardados, apresentando os rendimentos que eles podem alcançar à luz de três problemas interligados, referentes à prática dos arquitetos, às possibilidades de inserção social e profissional dos estrangeiros e a sua contribuição para a construção da cidade de São Paulo entre os anos 1930 e 1960.

A relação dialética entre pesquisa histórica e constituição de arquivos é também um dos aspectos tratados por Nilce Aravecchia-Botas no artigo Habitação pública e modernização capitalista: uma relação dialética entre fontes de pesquisa e procedimentos de análise, como se verá mais adiante. Antes de recuperá-lo, contudo, cumpre seguir com o enfoque mais detido a respeito da natureza dos arquivos a partir do texto apresentado por Amália Cristovão dos Santos, A América portuguesa sob as luzes do scanner: arquivos, reprodução e manipulação digital da cartografia histórica. Nesse caso, a escala de observação se amplia do edifício para o território e o enfoque desliza da organização dos arquivos para a difusão dos documentos, considerando a informatização da consulta e da produção de documentos cartográficos.

Como nos artigos anteriores, Amália dos Santos faz uma revisão historiográfica precisa, seguida de uma detida análise documental, para chamar a atenção para a importância de se pensar na produção, circulação e consumo da cartografia, desde a sua elaboração original até a sua digitalização, bem como de se empreender as análises a partir de problemas históricos bem definidos. Por meio de exemplos específicos, pondera que as transformações da informática que incidiram sobre os processos de reprodução, divulgação e manipulação de mapas não garantem em si novas descobertas ou pontos de inflexão na discussão historiográfica, se não forem observadas as questões anteriormente indicadas, mas aponta que elas permitem novas articulações entre dados de pesquisa, tirando da sombra agentes sociais antes ausentes na construção das narrativas.

Do território passamos à cidade com o artigo Figurações da cidade: um olhar para a literatura como fonte da história urbana, escrito por Ana Claudia Veiga de Castro. A autora foca na escala urbana e atenta para um documento que tem sido recorrente na história da cidade, a literatura, cujos desafios para sua incorporação impõem um conjunto de reflexões de ordem teórico-metodológica. Ao recuperar alguns autores que se apoiaram na literatura para pensar ou tratar da cidade moderna, ainda hoje importantes dentro e fora desse campo, tais como Raymond Williams, Marshall Berman, Antonio Candido, Nicolau Sevcenko, Flora Süssekind, Maria Stella Bresciani, constrói um panorama dos estudos urbanos como um campo ampliado que engloba a História, a Sociologia e as críticas literária e 
urbana, em busca de precisar a maneira com que a literatura foi e é mobilizada em cada um desses trabalhos. Alinhada com a perspectiva histórica cultural urbana que, de algum modo, atravessa todos esses trabalhos, Ana Castro retoma as pesquisas que desenvolveu inicialmente sobre São Paulo, e a mais recente, voltada para a América Latina, apresentando reflexões sobre o uso da literatura como documento, seja através de experiências empíricas, seja por meio de investigações de cunho teórico, seja ainda na articulação entre as duas abordagens, em sua pesquisa atual.

Se no texto de Ana Castro a literatura é o documento central para se pensar a cidade, no artigo Patrimônio cultural e escrita da história: a hipótese do documento na prática do Iphan nos anos 1980, de Flávia Brito do Nascimento, a própria cidade é tomada como fonte central da reflexão. Tal apropriação surge na esteira das revisões historiográficas empreendidas a partir dos Annales pelos próprios técnicos do Iphan, que definiriam cidades como Laguna, em Santa Catarina, e Cuiabá, em Mato Grosso, além de localidades urbanas como o Morro da Conceição e a Praça XV de Novembro no Rio de Janeiro, como fontes históricas, justificando por sua potência documental então atribuída a necessidade de seus tombamentos. Tomando o caso de Laguna, Flávia Brito mostra como essa concepção implicou e foi motivada por um entendimento novo não só do espaço urbano, como do próprio tombamento, no momento exato em que aquela revisão historiográfica conhecia novos desdobramentos que ressignificariam os artefatos em suas diversas escalas.

As mudanças nas políticas patrimoniais e o tenso diálogo estabelecido com a população atravessam também o artigo de Fernando Atique, A midiatização da (não) preservação: reflexões metodológicas sobre sociedade, periodismo e internet a propósito da demolição do Palácio Monroe. Sem perder de vista a escala da cidade, o autor apresenta o complexo circuito social que envolveu a produção do Palácio Monroe no início do século XX, a recusa da proposta de seu tombamento e a consequente demolição do edifício nos anos 1970, bem como sua rememoração contemporânea. Para tanto, Atique se vale não apenas de documentos oficiais, advindos dos órgãos de preservação e da administração estatal ou do discurso autorizado dos arquitetos, mas de uma plêiade de fontes documentais, algumas delas já incorporadas pelos historiadores do campo, como revistas e jornais, outras novas, advindas dos processos de informatização, como sites, blogs e páginas produzidas por um público na maioria dos casos leigo, mas interessado pela cidade, seu passado e patrimônio. Tais documentos dão espaço para outras vozes, à semelhança do artigo de Santos, que, neste caso, reforça o argumento de que a preservação não é um problema técnico, restrito ao campo da arquitetura e do urbanismo, mas antes de tudo um problema social, algo que ressoa nos artigos de Costa e Brito.

O esforço de manejar um conjunto amplo e interligado de documentos - projetos e planos, fotografias, entrevistas, periódicos, documentos administrativos, a própria arquitetura, entre outros - foi enfrentado também por Nilce Aravecchia com o intuito de investigar a produção pública de habitação social no Brasil entre 
os anos 1930 e 1964. Esse empreendimento foi apoiado e contribuiu para constituição do acervo do Grupo Pioneiros da Habitação Social no Brasil, coordenado por Nabil Bonduki, cujos documentos foram revistos à luz de novas questões e aportes teóricos, que ajudaram a construir uma interpretação própria sobre essa produção, dentro do processo de consolidação do sistema capitalista, e considerando suas contradições, limitações, mas também potências, tanto disciplinares quanto sociais.

Como se vê por esta Introdução, há entre os artigos um conjunto de pressupostos teórico-metodológicos comuns, fruto de um trabalho que se buscou coletivo, sem perder de vista as especificidades de cada uma das pesquisas. Trabalho que tem compromissos com a investigação acadêmica, sem abandonar os seus sentidos políticos, construído nos arquivos, mas também em sala de aula, e que quer ser uma contribuição para aqueles que se dedicam a pensar a história da cidade e da arquitetura a partir de uma perspectiva cultural ampliada. 


\section{REFERÊNCIAS}

CASTRO, Ana Claudia Veiga de; SILVA, Joana Mello de Carvalho e. História e historiografia da arquitetura e da cidade. In: CABRAL, Claudia Costa; COMAS, Carlos Eduardo (Orgs.). ENANPARQ, Estado da Arte, 4., Porto Alegre, 2016. Anais... Porto Alegre: PROPAR/UFRGS, 2016. Disponível em: <https://enanparq2016.files.wordpress.com/2016/09/s42-00-castro-amello-j.pdf>. Acesso em: ago. 2016.

LE GOFF, Jacques. Documento/Monumento. In: História e memória. Tradução de Irene Ferreira, Bernardo Leitão e Suzana Ferreira Borges. Campinas: Editora da Unicamp, 1990. p. 535-553.

LEPETIT, Bernard. Por uma nova História Urbana. Seleção de textos, revisão crítica e apresentação de Heliana Salgueiro. Tradução de Cely Arena. São Paulo: Edusp, 2001.

MENESES, Ulpiano Bezerra de. Fontes visuais, cultura visual, história visual. Balanço provisório, propostas cautelares. Revista Brasileira de História, v. 23, n. 45, p. 11-36, jul. 2003.

Morfologia das cidades brasileiras: introdução ao estudo histórico da iconografia urbana. Revista USP: Dossiê Brasil dos viajantes. São Paulo, SP: USP, CCS, n.30, jun./ ago.,1996.

NOVAIS, Fernando; SILVA, Rogério. Introdução. In: (Orgs.). Nova História em perspectiva. São Paulo: Cosac \& Naify, 2011. p. 7-70.

REVEL, Jacques. Jogos de escalas: a experiência da microanálise. Rio de Janeiro: Editora FGV, 1996.

SAlGUEIRO, Heliana Angotti. Apresentação. In: LEPETIT, Bernard. Por uma nova História Urbana. Seleção de textos, revisão crítica e apresentação de Heliana Salgueiro. Tradução de Cely Arena. São Paulo: Edusp, 2001. p.11-30.

Artigo apresentado em 03/10/2016. Aprovado em 27/12/2016. 